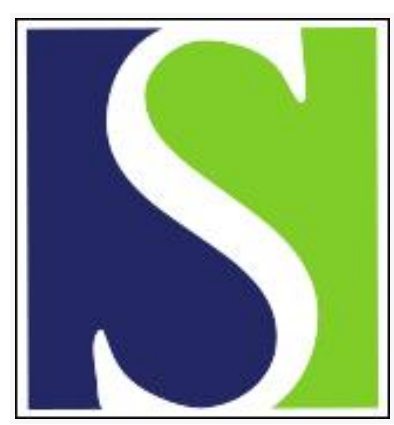

Scand J Work Environ Health 1987;13(3):193-196

https://doi.org/10.5271/sjweh.2066

Issue date: Jun 1987

\title{
Is passive smoking increasing cancer risk?
}

by Vainio $\mathrm{H}$

This article in PubMed: www.ncbi.nlm.nih.gov/pubmed/3303311

\section{(c) (1)}




\title{
Is passive smoking increasing cancer risk?
}

\author{
by Harri Vainio, MD ${ }^{1}$
}

\begin{abstract}
VAINIO H. Is passive smoking increasing cancer risk? Scand J Work Environ Health 13 (1987) 193-196. Although the amounts of environmental tobacco smoke absorbed by passive smokers are small in comparison to those absorbed by active smokers, the fact that (almost) everybody in modern society is exposed makes it an important public health problem. The many published epidemiologic studies are all consistent with a $30 \%$ increase in the risk of lung cancer. This increase is plausible in relation to the exposure levels derived from various biological dose indicators. The risks of passive smokers are, of course, smaller than those of active smokers, but it is generally accepted that involuntary risks should be much smaller than those that are self-inflicted. Even a relative risk for lung cancer of 1.3 due to passive smoking would constitute an increase on the order of 1 in 1000 in the lifetime risk. Normally, this level would be considered "unacceptable," and preventive measures should be taken.
\end{abstract}

Key terms: cotinine, epidemiologic, experimental, lung cancer, review, tobacco smoke.

Nonsmokers are exposed to environmental tobacco smoke in indoor areas such as offices, in public places like bars and restaurants, and in private residences. These people are thus exposed involuntarily to an established human carcinogen (15).

The answers to questions of whether nonsmokers exposed to environmental tobacco smoke are at increased risk of lung cancer and whether the doseresponse relationship is similar to that for smokers depend on whether there is a threshold dose of cigarette smoke below which there is no increase in risk. Cigarette smokers' risk of lung cancer is directly related to the number of cigarettes smoked. At low to average levels of smoking, this relationship is approximately linear, with no apparent threshold (9). For smokers, an increase in exposure leads to an increase in risk as long as additional tobacco smoke (whether from active or passive smoking) reaches the bronchial epithelium. Biological theory and current evidence concerning low-dose exposures to carcinogens do not provide evidence of a threshold, and it is generally considered to be unlikely. If there is no threshold, it follows that exposure to low concentrations of tobacco smoke, such as that experienced by nonsmokers exposed to environmental tobacco smoke, will cause an increased risk of lung cancer. The risk will, of course, be expected to be much smaller than that associated

\footnotetext{
1 International Agency for Research on Cancer, Lyon, France.
}

Present address and address for reprints: Dr $\mathrm{H}$ Vainio, Institute of Occupational Health, Topeliuksenkatu 41 a A, SF-00250 Helsinki, Finland. with active smoking, because of the much lower exposure of the bronchial epithelium to tobacco smoke. In this short review, some of the main arguments for the carcinogenicity of environmental tobacco smoke are discussed.

\section{Environmental tobacco smoke}

Environmental tobacco smoke occurs in houses, at workplaces, and in public places. It is a complex mixture of compounds formed during the pyrolysis and pyrosynthesis of tobacco products. More than 3800 chemicals have been identified in tobacco smoke, including at least 40 known carcinogens (15). Tobaccospecific components include nicotine, some $\mathrm{N}$-nitrosamines, and probably some aromatic amines and $N$-heterocyclic hydrocarbons. Environmental tobacco smoke originates from the smoldering of the tobacco product between puffs, known as sidestream smoke, from smokers' exhaled smoke, and from smoke that escapes from the burning core during puff drawing. The various components are released into the environment and diluted with ambient air. Undiluted sidestream smoke contains higher concentrations of some components of tobacco smoke than does undiluted mainstream smoke, including carcinogenic volatile nitrosamines and aromatic amines. Smokers, because of their proximity to the source, usually inhale more environmental tobacco smoke than nonsmokers; however, the exact differences in the exposure level between smokers and nonsmokers are not known. Model studies with mainstream smoke have shown that more than $90 \%$ of some volatile hydrophilic components (eg, acetaldehyde) is retained after inhalation by the smoker (6). Therefore, one may assume that a large 
fraction of the hydrophilic agents in the vapor phase of environmental tobacco smoke is also retained when smoke-polluted ambient air is inhaled. Of the hydrophobic components of the vapor phase of mainstream smoke, eg, carbon monoxide, the retained fraction depends on the depth of inhalation, but it hardly ever exceeds $50 \%$ (7). An active smoker generally retains more than $90 \%$ of mainstream particles, whereas a nonsmoker appears to retain a smaller fraction (13).

Relatively high concentrations of radon and radon daughters have been found in indoor air in houses in several countries (26). In the presence of an aerosol like tobacco smoke, some of the short-lived radon daughters are attached to particles and therefore remain available for inhalation to a much greater extent than would otherwise be the case. Indoor concentrations of radon daughters can be more than double in the presence of tobacco smoke (2).

In summary, comparison of the chemical composition of the smoke inhaled by active smokers with that inhaled by passive smokers suggests that the carcinogenic and toxic effects would be qualitatively similar.

\section{Experimental data}

Several short-term tests have been performed to evaluate the genotoxicity of cigarette smoke $(8,15,27)$. Most of them have evaluated the effects of cigarettesmoke condensate. A recent study has shown that sidestream smoke is also mutagenic in a system in which the smoke was tested directly on bacterial plates (28). The particulate matter of environmental tobacco smoke collected from smoky indoor environments was also mutagenic in the Salmonella/microsome assay (22, 23). The average mutagenicity of indoor air per cubic meter has been correlated significantly with the number of cigarettes smoked (21). Mainstream cigarette smoke condensate (collected on filters) has been shown to be highly active in inducing sister chromatid exchanges in Chinese hamster ovary cells in vitro (31).

A working group of the International Agency for Research on Cancer (15) concluded that there is sufficient evidence that both inhalation of tobacco smoke and topical application of tobacco-smoke condensate cause cancer in experimental animals. It found that studies with hamsters and rats have shown that the inhalation of whole smoke results in the induction of respiratory tract cancers, whereas cigarette-smoke condensate was found to induce skin cancer in mice and rabbits after skin application and lung cancers in rats after intrapulmonary injection.

In summary, the data demonstrate that cigarette smoke is carcinogenic in animals. However, the carcinogenic potency of environmental tobacco smoke cannot be estimated with any confidence. The material collected from smoky rooms is mutagenic in many test systems.

\section{Biochemical markers of exposure}

Cotinine, a metabolite of nicotine, although not considered itself to be a carcinogen, is a useful marker of exposure to tobacco smoke, whether through active or passive smoking. Urinary cotinine is thus at present the best marker for measuring tobacco smoke intake by nonsmokers because it is highly sensitive and specific for tobacco smoke. Wald \& Ritchie (36) have shown that "unexposed" individuals have, on the average, $8.5 \mathrm{ng} / \mathrm{ml}$ cotinine in their urine. Since virtually the only source of nicotine and cotinine in body fluids is tobacco products, primarily through exposure to tobacco smoke, it follows that "unexposed" individuals are in fact exposed to environmental tobacco smoke. The relative urinary cotinine levels in three groups nonsmoking men married to nonsmoking women, nonsmoking men married to smoking women, and men who are active smokers - were in the ratio $1: 3: 215$. On the assumption of a similar half-time of cotinine in smokers and nonsmokers, the exposure of nonsmokers to environmental tobacco smoke would be about $1 \%$ of that of active smokers $(12,16,17,36)$. If it is assumed that active smokers consume 20 cigarettes per day and the relationship between the number of cigarettes smoked per day and the urinary cotinine level is linear, nonsmokers are exposed to a smoke equivalent of roughly 0.2 cigarettes a day. However, preliminary data suggest that cotinine elimination in nonsmokers exposed to environmental tobacco smoke is slower than cotinine elimination in active smokers (33).

Similar work in Japan has suggested that nonsmokers have relatively high cotinine levels - about oneseventh the levels of average Japanese smokers (24). The reason for the difference is not known, but, if the difference is real, passive smokers in Japan would have higher exposure and, consequently, a higher risk of lung cancer.

Whether urinary cotinine measurements can provide a reasonable basis for making a first estimate of the risk for lung cancer arising from exposure to environmental tobacco smoke depends in part on whether the intake of the relevant carcinogens in active and passive smokers is directly proportional to the relevant intake of nicotine, from which cotinine is derived. The lack of knowledge about which specific components are responsible for causing lung cancer and the present inability to measure their intake directly create uncertainty. But, as a first approximation, it is reasonable to assume proportionality.

On the basis of such measurements, the risk for lung cancer from exposure to environmental tobacco smoke among male nonsmokers, on the assumption of a linear dose-response relationship, would be $10-15 \%$, given that the relative risk of average active male smokers is 10 to 15 times greater than that of nonsmokers.

In summary, it has been convincingly shown by the use of biochemical markers that nonsmokers absorb 
up to about $1 \%$ of the dose of tobacco smoke received by smokers. These data are, however, too imprecise to allow a quantitation of risk to be made.

\section{Epidemiologic studies of passive smokers}

In recent years, a number of epidemiologic studies has been published on passive smoking and lung cancer in nonsmokers. (For reviews, see references 25, 29, 32.) Three of the studies are of the cohort type, in which data on smoking habits were obtained for several thousand married couples or household members $(10,11$, 14). The cause-specific mortality was then followed for some years, and an analysis made of the lung cancer risk among nonsmokers in relation to the smoking habits of the smokers in the household. Eleven studies are of the case-referent type $(1,3-5,18-20,30,34$, $35)$. The relative risk for lung cancer associated with passive smoking lies above 1.0 in most of these studies.

Considering the evidence as a whole, exposure to environmental tobacco smoke increases the incidence of lung cancer in nonsmokers. Estimates of the magnitude of the increased risk vary. For populations in Europe, Asia, and North America the risk of lung cancer is roughly $30 \%$ higher for nonsmoking spouses of smokers than it is for nonsmoking spouses of nonsmokers, although the patterns and extent of exposure may not be the same in different communities and countries. The risk estimates are derived almost exclusively from comparisons of persons identified as exposed and unexposed on the basis of their spouses' smoking habits.

The studies on passive smoking and cancer contain the potential for many random and systematic errors because (i) insufficient numbers of nonsmoking lung cancer cases are available for analysis; (ii) diagnoses of lung cancer are often inaccurate; (iii) information about exposure is derived only by inference (ie, marriage); (iv) possible confounding due to other indoor air pollutants, such as radon, has usually not been considered; (v) ex-smokers may be misclassified as nonsmokers; and (vi) there are probably differences in the accuracy of passive smoke histories between living and deceased subjects.

Certain errors in the reporting of smoking habits have probably contributed to the results obtained in these epidemiologic studies. Classification of current or ex-smokers as nonsmokers would tend to produce an observed relative risk that is larger than the true risk. Underestimation of the increased risk might be introduced by the existence of some exposure of the supposedly unexposed population to environmental tobacco smoke. Taking both types of errors into account produces an estimate of excess lung cancer risk for nonsmokers married to smokers, as compared with completely unexposed individuals, that is similar to the relative risk observed in the epidemiologic studies considered.

The interaction between exposure to environmental tobacco smoke and living in houses in which there is a greater risk of radon exposure has been examined in one study (30). For all histological types of lung cancer, the relative risks for passive smoking and radon exposure were 1.2 [95\% confidence limits $(95 \% \mathrm{CL}$ ) $0.6-2.6$ ] and 1.4 (95\% CL 0.4-5.4), respectively. For women who had been married to a smoker and who had lived in a house presenting a greater risk of radon exposure, the relative risk was $2.5(95 \% \mathrm{CL}$ $0.8-8.5$ ), suggesting a positive interaction between these two variables.

Many of the results obtained may thus have been biased to some extent; however, bias is not considered to account for all of the increased risk $(25,30)$. The best estimate of a committee of the United States National Research Council (25), allowing for reasonable misclassification, is an adjusted increased risk for lung cancer of about $25 \%$ (ie, rate ratio $=1.25$ ) for nonsmokers married to smokers, when compared to that of nonsmokers married to nonsmokers.

For cancers of sites other than the lung, there is no consistent evidence of an increased risk due to passive smoking $(15,25)$.

\section{Quantitative lifetime risk estimate}

On the assumption that the observed summary rate ratio of 1.3 for lung cancer is causal, the lifetime attributable fraction for never smokers has been calculated to be $390-990$ per 100000 deaths. For exsmokers, the estimate was $520-2030$ per 100000 , and for continuing smokers between 580-3 330 per 100000 (26). The lower estimate of risk for passive smoking is therefore at a significant level of 3.9 per 1000 , a risk which normally triggers regulatory action in many societies.

\section{Epilogue}

The relative abundance of data reviewed in this report, their cohesiveness, and their biological plausibility allow the judgment that passive smoking can cause lung cancer in nonsmokers. It is known that environmental tobacco smoke contains carcinogens, the exposure of nonsmokers to ambient smoke is large so that an increased lung cancer risk can be expected, and human epidemiologic studies have demonstrated an increased risk of lung cancer in passive smokers.

\section{References}

1. Akiba S, Kato H, Blot, WJ. Passive smoking and lung cancer among Japanese women. Cancer Res 46 (1986) 4804-4807. 
2. Bergman $\mathrm{H}$, Edling $\mathrm{C}$, Axelson, O. Indoor radon daughter concentrations and passive smoking. In: Berglund B, Lindvall T, Sundell J, ed. Proceedings of the 3rd International Conference on Indoor Air Quality and Climate, Stockholm, August 20-24. Volume 2 (Radon, passive smoking, particulates and housing epidemiology). Swedish Council for Building Research, Stockholm 1984, pp 79-84.

3. Brownson, RC, Reif JS, Keefe TJ, Ferguson SW, Pritze JA. Risk factors for adenocarcinoma of the lung. Am J Epidemiol 125 (1978) 25-34.

4. Chan WC, Fung SC. Lung cancer in non-smokers in Hong Kong. In: Grundmann E, ed. Cancer campaign Volume 6 (Cancer epidemiology). Gustav Fischer Verlag, Stuttgart 1982, pp 199-202.

5. Correa P, Pickle LW, Fontham E, Lin Y, Haenszel W. Passive smoking and lung cancer. Lancet 2 (1983) 595-597.

6. Dalham T, Edfors M-L, Rylander R. Month absorption of various compounds in cigarette smoke. Arch Environ Health 16 (1968) 831-835.

7. Dalham T, Edfors M-L, Rylander R. Retention of cigarette smoke components in human lungs. Arch Environ Health 17 (1968) 746-748.

8. DeMarini DM. Genotoxicity of tobacco smoke and tobacco smoke condensate. Mutat Res 144 (1983) $59-89$.

9. Doll R, Peto R. Cigarette smoking and bronchial carcinoma: Dose and time relationships among regular smokers and lifelong non-smokers. J Epidemiol Community Health 32 (1978) 303-313.

10. Garfinkel L. Time trends in lung cancer mortality among nonsmokers and a note on passive smoking. J Natl Cancer Inst 66 (1981) 1061-1066.

11. Gillis CR, Hole DJ, Hawthorne VM, Boyle P. The effect of environmental tobacco smoke in two urban communities in the west of Scotland. Eur J Respir Dis 65 (1984): suppl 133, 121-126.

12. Haley NJ, Axelnad CM, Tilton KA. Validation of selfreported smoking behaviour: Biochemical analyses of cotinine and thiocyanate. Am J Publ Health 93 (1983) 1204-1207.

13. Hiller FC. Deposition of sidestream smoke in the human respiratory tract. Prev Med 13 (1984) 602-607.

14. Hirayama T. Non-smoking wives of heavy smokers have a higher risk of lung cancer: A study from Japan. $\mathrm{Br}$ Med J 282 (1981) 183-185.

15. International Agency for Research on Cancer. Tobacco smoking. Lyon 1986. (IARC monographs on the evaluation of the carcinogenic risk of chemicals to humans, volume 38 ).

16. Jarvis MJ, Russell MAH. Measurement and estimation of smoke dosage to non-smokers from environmental tobacco smoke. Eur J Respir Dis 65 (1984): suppl 133, $68-75$.

17. Jarvis MJ, Tunstall-Pedoe H, Feyeraband C, Vesey C, Saloojee Y. Biochemical markers of smoke absorption and self-reported exposure to passive smoking. J Epidemiol Community Health 38 (1984) 335-339.

18. Kabat GC, Wynder EL. Lung cancer in nonsmokers. Cancer 53 (1984) 1214-1221.

19. Koo LC, Ho JCH, Lee N. An analysis of some risk factors for lung cancer in Hong Kong. Int $\mathbf{J}$ Cancer 35 (1985) 149-155.

20. Lee PN, Chamberlain J, Alderson MR. Relation of passive smoking to risk of lung cancer and other smoking-associated diseases. $\mathrm{Br} \mathrm{J}$ Cancer 54 (1986) 97-105.

21. Lewtas J, Goto S, Williams K, Chuang JC, Petersen BA, Wilson NK. The mutagenicity of indoor air particles in a residential pilot field study. Atmos Environ (in press).

22. Ling PI, Löfroth G, Lewtas J. Mutagenic determination of passive smoking. Toxicol Lett 35 (1987) $147-151$

23. Löfroth G, Nilsson L, Alfheim I. Passive smoking and urban air pollution: Salmonella/microsome mutagenicity assay of simultaneously collected indoor and outdoor particulate matter. In: Waters MD, Chernoff N, Nesnow S, ed. Short-term bioassays in the analysis of complex environmental mixtures, III. Plenum, New York, NY 1983, pp 515-525.

24. Matsukura S, Taminato T, Kitano N, Seino Y, Hamada $H$, Uchihashi M, Nakajima $H$, Hirata Y. Effects of environmental tobacco smoke on urinary cotinine excretion in nonsmokers. N Engl $\mathrm{J}$ Med 311 (1984) $828-832$.

25. National Research Council. Environmental tobacco smoke - Measuring exposures and assessing health effects. National Academy Press, Washington, DC 1986.

26. Nero AV, Sextro RG, Doyle SA, Moed BA, Nazaroff WW, Revzan KL, Sehwehr MB. Characterizing the sources, range and environmental influence of radon-222 and its decay products. Sci Total Environ 45 (1985) 233-244.

27. Obe G, Heller W-D, Vogt H-J. Mutagenic activity of cigarette smoke. In: Obe $G$, ed. Mutations in man. Springer-Verlag, Berlin (West) 1984, pp 223-246.

28. Ong T, Stewart J, Whong WZ. A simple in situ mutagenicity test system for detection of mutagenic air pollutants. Mutat Res 139 (1984) 177-181.

29. Pershagen $G$. Review of epidemiology in relation to passive smoking. Arch Toxicol 9 (1986): suppl, 63-73.

30. Pershagen G, Hrubec Z, Svensson C. Passive smoking and lung cancer in Swedish women. Am J Epidemiol 125 (1984) $17-24$.

31. Salomaa S, Alfheim I, Leppanen A. Genotoxic effects of smoke emissions in mammalian cells. Environ Int 11 (1985) 311-316.

32. Saracci R. Passive smoking and lung cancer. In: Zaridze D, Peto R, ed. Tobacco: A major international health hazard. International Agency for Research on Cancer, Lyon 1986, pp 173-182. (IARC scientific publications no 74).

33. Sepkovic DW, Haley WJ, Hoffmann D. Elimination from the body of tobacco products by smokers and passive smokers. J Am Med Assoc 256 (1986) 863. (Letter).

34. Trichopoulos D, Kalandidi A, Sparros L, MacMahon B. Lung cancer and passive smoking. Int J Cancer 27 (1981) $1-4$

35. Trichopoulos D, Kalandidi A, Sparros L. Lung cancer and passive smoking: Conclusion of Greek study. Lancet 2 (1983) 677-678.

36. Wald NJ, Ritchie C. Validation of studies on lung cancer in nonsmokers married to smokers. Lancet 1 (1984) 1067.

Received for publication: 30 March 1987 